\title{
Reflexiones sobre el trabajo Psicosocial
}

Entrevista a Jorge Ordóñez ${ }^{1}$

Profesor tiempo completo Departamento de Estudios Psicológicos

Universidad Icesi

Por:

Juan Sebastián

Castillo
Mónica Alexandra Ramírez G.

Estudiante de Ciencia Política y Sociología

juansebastiancastillocastro@gmail.com

monica10ramirez@gmail.com

Entrevista recibida el 12/03/2018 y aprobado el 13/03/2018VV

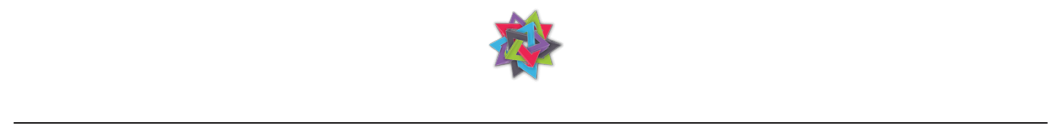

Cómo citar este artículo:

Castillo Castro, J., \& Ramírez Guevara, M.(2018).

Reflexiones sobre el trabajo Psicosocial. Trans-

Pasando Fronteras, (11).

${ }^{1}$ Psicólogo - Universidad del Valle, 1993. Especialización en Teoría y Métodos de Investigación - Universidad del Valle, 1996. Especialización en investigación en Docencia Universitaria - Universidad San BuenaventuraCali, 2001. Máster en Sociología - Universidad del Valle, 2003. Ph.D en humanidades - Universidad del Valle,2016. 


\section{Juan Sebastián Castillo (JSC): Desde su experiencia ¿Cuáles son los principales retos del ejercicio psicológico?}

Jorge Ordoñez (JO): Creo que hay una idea importante en el ejercicio de la psicología, que es una disciplina de muchas tradiciones, escuelas, etc... Que ha tenido un importante desarrollo teórico, en Europa, América y recientemente en Latinoamérica.

Es importante que la psicología nos sea útil para entender problemáticas locales y regionales. Hay una gran teoría que es muy útil y que hace parte del aprendizaje de la psicología. Pero, esa gran teoría ha de poder serles útil para entender las problemáticas que nos tocan a nosotros como sociedad. Entonces, puede haber una tendencia de la psicología a seguir programas de investigación en planteamientos que son de otra parte.

Yo creo que ese no es el camino, hay que hacer psicología para los problemas de la región, de Cali y del Valle del Cauca. Sin prescindir de la gran teoría ni de lo útil que puedan ser las diferentes disciplinas psicológicas para abordar este tipo de asuntos.

JSC: ¿Usted creería que también hay que hacer una producción teórica para el contexto colombiano?

JO: La investigación científica se hace para producir teoría, aunque algunos se les olvida, uno hace investigación científica para avanzar en la compresión teórica de problemáticas sociales y psicológicas. Efectivamente, necesitamos producir teoría sobre los problemas colombianos, tenemos problemas muy graves de integración social, violencia, adicciones, y enfermedades mentales. 
Colombia es un país que tiene graves problemáticas psicológicas y sociales, por ello los psicólogos estamos en mora de producir más y más conocimiento, y teoría, sobre este tipo de problemas.

\section{JSC: Respecto a este tipo de problemáticas ¿Cómo cree usted que debe articularse la psicología con otras disciplinas? Es decir, ¿se podría hablar de la interdisciplinariedad como un reto?}

JO: Si vamos a abordar el problema de la salud mental, hay que tener un dialogo muy fluido con psiquiatras, médicos, y profesionales en las áreas de la salud. Si vamos a abordar la problemática de la violencia, el dialogo debe confluir con antropólogos sobre las dimensiones estructurales de la violencia, sociólogos acerca de conectividad social, etc... Es muy importante un dialogo, no sé si interdisciplinario, la palabra suena bien, pero a veces ocurre que cada cual habla, y solo busca que lo dejen hablar; uno no ve que esos discursos se integren, el psicólogo habla su rollo, el ingeniero habla su rollo, y el sociólogo por otro lado, y todo el mundo queda contento. Para mi ese no es el ejercicio, lo que hay que hacer es encontrar campos de frontera porque hay problemas psico-sociales, o psico-culturales, y hay que crear un arsenal cultural que nos permita ir tranquilamente de una disciplina a otra.

También, hay que encontrar modelos teóricos y metodológicos que no sean incomparables o que no haya una inconmensurabilidad de paradigmas, porque si alguien habla desde el lenguaje de la matemática pues eso no dialoga con un lenguaje cualitativo o etnográfico, entonces hay que buscar la manera de que eso sea posible y yo creo que es posible. De hecho, creo que lo más interesante de la psicología son precisamente esos campos de frontera. 
Mónica Ramírez (MR): ¿Cuáles han sido los problemas o las preocupaciones que usted ha abordado en su ejercicio profesional?

JO: Yo he tenido temas relativamente exóticos, durante los inicios de mi carrera trabaje sobre la medicina chamaníca, un tema antropológico; luego me oriente al tema de las pandillas y la violencia, ese es el tema que más he consistentemente trabajado. Trabajando con las pandillas, llegamos a una discusión que estaba en otro ámbito, el ámbito jurídico, de la filosofía del derecho, etc... el cual es, el campo de la justicia restaurativa. Es allí donde fundamentalmente he desarrollado mi investigación que es el punto de vista que podría llamarse, antropológicamente, dimensiones culturales de la violencia. Pero, hablando de eso hay que tener un pie en la antropología, en la sociología, en la psicología; para poder construir teóricamente un problema que pueda ser descrito y enfrentado teóricamente en la arena.

\section{JSC: ¿Ha identificado alguna limitación a la hora de tener con- tacto con las personas que pertenecen a las pandillas?}

JO: No es fácil trabajar con pandillas, cualquiera desde afuera mira y dice "es peligroso" y efectivamente puede serlo, pero hay maneras, y las maneras son las redes sociales, porque las comunidades tienen redes y maneras de comunicarse, de resolver, o integrarse. Esas redes formales e informales son aquellas en las cuales uno entra, yo entro a través de una fundación que trabaja con los muchachos, yo no voy a ir a buscarlos espontáneamente porque podía ser peligroso, sino que los muchachos han entrado ya en dialogo con unas señoras, las cuales los convencen de ir a unos talleres y en los talleres hay un programa y hay unos recursos, y hay un plan de la fundación. 
Así accede uno a ellos para poder hablarles, y verificar si la relación se conduce de manera adecuada o no hay ningún peligro. Los muchachos son muy respetuosos, cuando uno entra por la buena ellos son muy respetuosos, ellos siguen un código de honor que los obliga a respetar al interlocutor, a quererlo, y a cuidarlo. Entonces uno entra en una relación privilegiada con ellos, yo he llegado a andar la calle con ellos, por supuesto no delinquiendo pero una situación que uno no se imagina siendo totalmente foráneo, estar en Alfonso López o el jarillón conversando con este grupo de muchachos, con las pandillas de allá, sin sentir que uno está en peligro porque realmente ellos te están cuidando. Hay que caerles bien, ser empático, honesto, y hay que crear una relación de respeto muto, hay que crear lo que se llama en antropología, un raport; pero una vez que se crea el dialogo es muy fluido, y efectivamente no tiene demasiados riesgos.

\section{JSC: ¿Siente que para establecer el raport hay que desdibujar un poco la postura de la academia con la que uno suele llegar?}

JO: Si. Uno pertenece a la academia, pero cuando uno va al campo es ignorante, de hecho si uno se lleva las teorías a explicarlas no ocurre nada. De hecho, cuando llegue no sabía cuáles eran las pandillas, ni que hacen, ni porque se matan, ni cuál es su vida, y lo que hice durante muchos años fue preguntarle todo eso ¿qué hacen? ¿Cuáles son los problemas que tienen? ¿Porque mataron a tal persona? ¿Qué hacen para sobrevivir? Yo no sabía nada de eso, no sabía nada de su ethos hasta que interactúe con ellos, ellos fueron mis maestros quienes me enseñaron, a ellos les gusta adoptar esa posición "este es un señor que no sabe nada de esto pues contémosle como somos". Es raro pero puede resultar divertido, alguna vez comentaba con los jóvenes en una panadería de Alfonso López, y llego una amiga de ellos que no sabía nada de 
mí, y ella no podía creer que yo estuviera ahí y decía "¿De dónde se consiguieron esta man?" Claro yo pertenezco a otro planeta, a otra clase social, a otro universo, y es muy extraño que yo este parchado con un grupo de pandilleros peligrosos, es muy raro y a ella le parecía divertidísimo, y ellos también tienen curiosidad por uno, somos personas de dos mundos que se encuentran.

\section{JSC: ¿Usted cree que su trabajo se había podido haber real- izado sin haber tenido contacto directo con ellos?}

Desde mi punto de vista no lo hubiera sido, hay maneras de aproximarse a los fenómenos, e incluso hay unas que se consideran más científicas que otras, que son asépticas y distantes, se puede hacer una gran teoría especulativa del fenómeno de pandillas mirando la marginalidad de ciertos sectores, se puede mirar las estadísticas de la violencia en sectores, se pude hablar con la policía sobre los porcentajes de la violencia producida por pandilleros, estos datos son importantes y bueno. Yo empecé con las estadísticas, pero el paso siguiente, inevitablemente, era preguntarles que pasaba; yo puedo tener índices de desarrollo o de necesidades básicas insatisfechas de los barrios en que ellos viven, pero la información de la dimensión cultural, psicológica, sociológica, creo que ya necesitaría acudir a ellos

\section{MR: En ese ejercicio de trabajar con la comunidad ¿existieron algún tipo de retos más allá de lo metodológico o como la inter- pretación de su posición en términos éticos?}

JO: Es una investigación relativamente compleja en términos éticos porque son delincuentes, porque el pacto de confidencialidad implica por ejemplo que no puedo hacerles firmar consentimientos informados, porque ellos me cuentan que han co- 
metido delitos, y yo no puedo grabarlos y pedirles que me firmen un papel consintiendo que yo use esa información, porque ya con eso, los Ilaman y los condenan. De entrada les digo que no vengo a averiguarles sus cosas, ni a hacer una investigación policial pero por favor no me cuenten detalles, yo no puedo saber detalles que los pongan en riesgo, no me cuenten que la próxima semana van a hacer una vuelta porque me toca denunciarlos, igual ellos saben cómo tener la cosa más o menos en secreto, si me cuentan cosas del pasado les digo que no me den nombres, a mí me interesa es el significado que ellos atribuyen a ese tipo de prácticas, es una relación compleja porque yo no puedo acolitar delitos, no puedo alcahuetearles -como dicen ellos - alguna vuelta. El compromiso cuando recorrimos los barrios, es que si van conmigo no se pongan a hacer cosas porque no puedo acolitarles.

Es frecuente que quien trabaje con pandillas les coja cariño a los muchachos, y los muchachos pueden llegar y decirle que le guarde armas, pero uno no puede exponerse a ese tipo de situaciones. Si alguno viene y le comenta a uno que acaba de cometer un delito, pues uno tiene la obligación ciudadana de denunciarlos, de dar a conocer a la justicia ese tipo de prácticas, por fortuna nunca tuve situaciones así, pero sé que le ocurren a quien trabaja con ellos.

Hay un padre muy famoso que una vez saco escondido a un muchacho que iba a buscar la policía, no se debe plantear las cosas de esa manera, por eso la frontera ética en este tipo de trabajo es muy complicada. Primero yo no debo dar a conocer de ninguna manera quienes son ellos, el anonimato es total, incluso yo no dejo que nadie pueda tener acceso a ese tipo de entrevistas, los nombres se perdieron, incluso a veces yo mismo no me acuerdo de los nombres, porque yo no debo permitir que eso se sepa, por eso no les hago firmar consentimientos informados. 


\section{JSC: ¿Cómo maneja la parte de presentar los datos en su trabajo?}

Yo les pongo otros nombres. En algún momento me decían que los nombres deben tener alguna equivalencia, pero yo no puedo permitir eso. No debo dar ningún tipo de conexión porque alguno de ellos todavía vive, y no se trata de eso, mi relación con ellos no se trata de ver en qué medida son delincuentes, sino en buscar como que significado atribuye a la violencia, y que manera tienen de construir su identidad, entonces yo nunca averiguo como lo haría un policía o un detective, porque ese no es mi trabajo

MR: Los científicos sociales tenemos eso de ir a las comunidades a sacar información e irnos sin dejar nada. ¿De qué manera se percibe eso en tu trabajo?

JO: No es sencillo, muchas veces la información no es clara, y la relación con estas comunidades tampoco es que sea fácil, a mí se me perdieron muchos pandilleros, los vi una vez y no los volví a ver, me ocurrió con frecuencia, puedo tener una entrevista con uno, y cinco con otro. De todas maneras, esta investigación surgió en un entorno favorable porque la Fundación Paz y Bien estaba interviniendo con los jóvenes, no fue una información que obtuve como etnógrafo solamente. Diseñamos un plan de acción con los pandilleros basado en la justicia restaurativa y lo que hicimos fue aterrizar al contexto cultural de las pandillas de agua blanca la manera como ellos perciben la violencia, el conflicto y la manera como podría haberse transformado.

La investigación nutrió el programa de intervención con ellos, nos dimos cuenta por ejemplo que en el discurso de los pandilleros siempre hay un foco de control externo, lo que a ellos les pasa, ellos ven la vida como algo que les ocurre sin que ellos in- 
tervengan en ella, todo el tiempo hablan de supersticiones mundo sobrenatural, amuletos, balas rezadas, cuerpos cerrados, protecciones con base en la santería, tiene una manera de narrar el entorno de la violencia de una manera mágico religiosa, tienen un código de honor del cual son víctimas siempre, ningún pandillero te dice que el ataco a alguien, todo es externo, y siempre dicen que si matan a alguien es porque se hizo matar.

No son responsables de su propia vida. ¿Por qué mataron a Carlitos? -porque el ángel de la guarda lo dejo tirado, no fue porque lo buscaran para matarlo, pero ellos saben que si, pero dicen que fue porque el ángel de la guarda no estaba con él, o se le quedo su amuleto. Esa externalidad de la narrativa pandillera nos hace pensar que hay que trabajar en el ejercicio contrario, que se asuman autónomos, cuando ellos son completamente heterónomos, hay que cambiarles el discurso generando autonomía, decirles que son responsables de lo que hacen, y se diseñaron talleres en esa dirección.

Para ellos el enemigo es una proyección psicológica, los que viven de la cuadra para allá son enemigos, no te han hecho nada, así son las cosas. Los niños dicen: mi hermano es enemigo, y de ahí heredan la rivalidad, a veces se arman las enemistades pero también es cierto que se heredan. Entonces, hay que enseñarles que la construcción del otro y la manera como se representa el enemigo hay que aterrizarla, enseñarles que también tiene mama, que también es persona, y que no todas las personas son malas, incluso podrían hablar, le pusimos un nombre complicado que se llama "construcción de alteridad" algo que no se entiende bien ni en las facultades de la universidad, la idea es que puedan ver al otro como otro ser humano, ahí diseñamos parte del programa de intervención. Finalmente diseñamos una línea de construcción de ciudadanía, ellos no saben que son ciudadanos, ni siquiera tienen 
cedula, nunca han ido al centro, muchos de ellos son analfabetas, la idea es restituirles la condición de ciudadanía, conseguirles cedula, explicarles que viven dentro de un estado, había un muchacho que no sabía quién era el presidente porque en su vida no habían ese tipo de problemas, el problema es cómo nos matamos unos a otro, a ellos hay que ofrecerles una red de apoyo emocional y que cubra sus necesidades para que se resocialicen y se envuelvan en otro tipo de relaciones distintas a ser una pandilla. Cuando les ofrecen eso ellos se animan, si usted no le ofrece nada por supuesto no pasa nada pero ellos responden, ser pandillero no es una dicha, no es rico ni maravilloso, se surge violencia, marginación, pobreza, les matan a los amigos, a ellos mismos, y demás.

JSC: ¿Uno de los retos pueda ser que esos insumos producidos a través del trabajo de campo, de la etnografía sean tenidos en cuenta en la implementación de política pública?

JO: Ha sido difícil, ha habido momentos en que la fundación no ha tenido recursos, porque depende de recursos de cooperación internacional o mecenazgo de familias de aquí de Cali y, eventualmente, contratos con fundaciones pero no ha sido una política consistente. Debería ser una política consistente porque el problema persiste, es más grave que cuando empezamos, en ese tiempo eran pelados muy marginales que encontraban como construir su masculinidad a partir de la violencia, una violencia muy ritualizada, e identitaria "los de este parche hemos ganado $x$ batallas de tales manera" se han transformado recientemente en una dinámica de vinculación con la delincuencia organizada, ya no son pandillas de muchachos bravos sino que están participando de las redes de micro tráfico, y son miles, que no tienen oportunidades, problemas en la escuela, con malas relaciones interfamiliares, que encuentran en el tráfico de drogas trabajo, algunos son expend- 
edores, otros campaneros y otros son sicarios. El problema es gravísimo y ni siquiera existe a nivel nacional una política pública para enfrentar el problema de la violencia urbana. Estamos todos enfocados en las FARC, en el proceso, y en el posconflicto, pero ¿han mirado la violencia en Armenia, Pereira, Cali? La violencia urbana es un problema gravísimo y no tiene una política pública, hay las labores de la policía que ubican bandas, realizan inteligencia, y judicializan, no estamos en contra de eso, pero esa no debe ser la única política, en vez de andar matando muchachos deberían andar pensando en cómo evitar que hagan ese tipo de cosas.

MR: Dices que siempre nos hemos enfocado en la violencia en el campo y hemos dejado de lado la ciudad. Teniendo en cuenta eso ¿Qué esperarías que hagan los futuros psicólogos, y los que ya están?

JO: Si, yo recomendaría que le pusieran mucha atención a los problemas regionales y locales, porque se nos están subiendo pierna arriba y no estamos haciendo nada y luego vamos a ser víctimas de una tasa de violencia y homicidio más altas, por fortuna en el proceso de paz han bajado, aunque en Cali siguen siendo persistentemente altas pero incluso en Cali al fin bajaron de una tasa muy alta a una un poquito más baja pero igualmente alta. Cali a diferencia de Medellín y Bogotá tiene una tasa demasiado estable que ni siquiera sabemos bien porque ocurre y no solamente son las pandillas, estas no son la causa principal, pareciera ser el narcotráfico ¿quiénes? ¿Cómo? En Cali no sabemos quiénes son los duros de las bandas, de pronto escarbando averigüemos unos nombres, y se averigua sobre algunas organizaciones criminales, algo se sabe, pero en general es una información que no circula, y que tenemos bastante desconocimiento. Yo sí creo que los Científicos sociales en Cali, siendo una de las ciudades más violentas del 
mundo y persistentemente violentas en los últimos años, deberíamos haber producido más de un libro y tener una producción consistente de porque Cali es una de la ciudad más violenta del mundo. Es rarísimo porque tenemos muchos científicos sociales y hemos estado demorados, sin querer decir con esto, que sea el único tema que hay que estudiar pero si hay cierta responsabilidad de que alguien se ocupe de eso de una manera consistente, más seria, porque para solucionarlo tenemos que conocerlo.

\section{JSC: ¿Agregaría algo que no le hayamos preguntado?}

JO: A mí me pasa que el tema es muy arduo y doloroso, uno también afronta cuidado de cuidadores, uno se involucra con los muchachos y cuando los matan le da mucho pesar, o cuando ve las vidas sin salida, condenados a la marginalización, a la pobreza, se vuelve doloroso. Tuve un momento en que me harté de escuchar tanto dolor y sufrimiento, fue ese momento en que me recluí en mi parte teórica de mi tesis, me dedique a escribir mi documento dejando de ir al barrio. Pero también hay una responsabilidad ética en decir: si uno conoce esa realidad hay que hacer algo para ver que podemos cambiar, para contribuir a que estos muchachos no sufran tanto. Esa ha sido nuestra labor y está plenamente justificado, yo trate de cambiar de tema porque me sentía agotado, pero no puedo, realmente por el recorrido que tengo, tengo la experticia y las teorías y uno viejo no arranca con un tema nuevo. Hay maneras, entre comillas, más amables para aproximarse a eso, yo creo que las dimensiones culturales de la violencia son muy interesantes, pero por ahí no son la violencia dura, entonces uno ve que tienen supersticiones religiosas, que son santeros, y es una manera más amable que nos ayuda a comprender mejor el fenómeno de la violencia. 
Ahora, voy a ocuparme de un tema complicado que es el de pandilleras, no sabemos nada de eso, pero uno investiga porque no sabe, si uno supiera probablemente no investigara, a mí me asusta porque no tengo idea, ni siquiera tengo un contacto directo con ellas, es un fenómeno que está avanzando, entonces hay que preguntarles a ellas, qué es lo que ocurre, por qué nadie sabe, y creo que es importante por lo menos tener noticia de eso. 